\title{
Walking the Line between Order and Chaos: A Teacher-Researcher's Reflection on Teaching Mathematics with Challenging Tasks in Primary Classrooms
}

\author{
James Russo $^{\mathrm{a}}$ \\ Corresponding author: James Russo (james.russo@monash.edu) \\ aFaculty of Education, Monash University, Clayton VIC 3168, Australia
}

Keywords: mathematics education, challenging tasks, mathematical knowledge for teaching, teacher reflection, teacher emotion, classroom management, task design

International Journal of Innovation in Science and Mathematics Education, 27(3), 14-24, 2019

\begin{abstract}
Encouraging teachers to incorporate challenging tasks into mathematics instruction is frequently implored by mathematics educators, due to its potential impact on student learning and persistence. However, there is evidence that teaching with such tasks is pedagogically demanding, particularly for less expert teachers. To support a developing dialogue around the experience of teaching with challenging tasks, I document my experience of teaching 84 lessons involving challenging tasks to three grades of year 1 and 2 students as part of a research project. Adopting a 'practitioner inquiry' lens, I analyse my reflective journal to reveal five themes: classroom management, maintaining and managing cognitive demand, time management, tensions between discussion objectives and tensions in task design. Implications for teacher professional learning are discussed.
\end{abstract}

\section{Introduction}

Teaching with challenging tasks appears to positively impact student learning outcomes and persistence (Sullivan et al., 2015), however it also requires substantial skill to successfully orchestrate (Ridlon, 2009; Thomas \& Monroe, 2006). Indeed, it has been noted that mathematics teachers need to develop specific sets of skills and specialist knowledge to orchestrate effective learning using challenging tasks (Giacomone, Beltrán-Pellicer, \& Godino, 2019). Not surprisingly, insufficient mathematical pedagogical content knowledge is one of the major impediments to teachers incorporating more challenging tasks into their teaching repertoire, and one of the barriers to maintaining a high level of cognitive demand as the task unfolds in the classroom (Charalambous, 2008). This issue is arguably exacerbated by the fact that, often in the literature, challenging tasks are presented and commentated on by teachers or teacher-educators, with exceptional expertise in mathematics instruction (Stein, Engle, Smith, \& Hughes, 2008), who make the experience of teaching with such tasks appear far smoother and less problematic than experienced by the typical teacher.

In order to support a developing dialogue around the realities of teaching with challenging tasks in the classroom, I present my own experience of teaching two units of work, incorporating 28 challenging tasks taught to three composite classes of Year 1 and 2 students $(28 \times 3=84$ lessons $)$ as part of my PhD project. The data I present in this paper draws heavily on a reflective journal I maintained during the teaching process. As a practitioner with a passion for mathematics instruction, but with perhaps less experience than is typical for individuals providing such commentaries (at the time of delivering these units, I was in my fourth year of teaching, and my second year in a part-time 
role as a mathematics specialist), I hope to bring a somewhat different perspective to the discussion. The purpose of the paper then is to explore one practitioner's reflections of teaching intensively with challenging tasks in the early years of schooling.

\section{My background and project}

I came to primary teaching as a mature age student with a background in social policy analysis and evaluation in the private and public sectors. After spending two years full-time as a classroom teacher (teaching Year 1 and 2 students), I was given an opportunity to work in a role as a primary mathematics specialist ( 2 days per week) whilst I undertook a $\mathrm{PhD}$ in mathematics education. This specialist role had a focus on number and algebra, and involved developing and implementing a program to support mental computation in the primary classroom, particularly amongst students in the early to middle years of schooling (see Russo, 2015a). In this specialist role, I developed an interest in the recent work of Peter Sullivan and colleagues, and began experimenting teaching with challenging tasks; initially using tasks designed by others, before beginning to design my own tasks. This combination of playing with challenging tasks in the classroom whilst simultaneously reading and thinking about reform-oriented approaches to teaching mathematics at university (e.g., Stein et al., 2008) helped inspire my $\mathrm{PhD}$ project.

To provide some context for the rest of the paper, I will briefly describe my project. For readers wanting more detail, a more comprehensive summary, including my findings, has been published elsewhere (Russo \& Hopkins, 2017a), as have additional examples of the types of challenging tasks employed (e.g., Russo, 2015b, 2016, 2019).

\section{Task-First Approach}

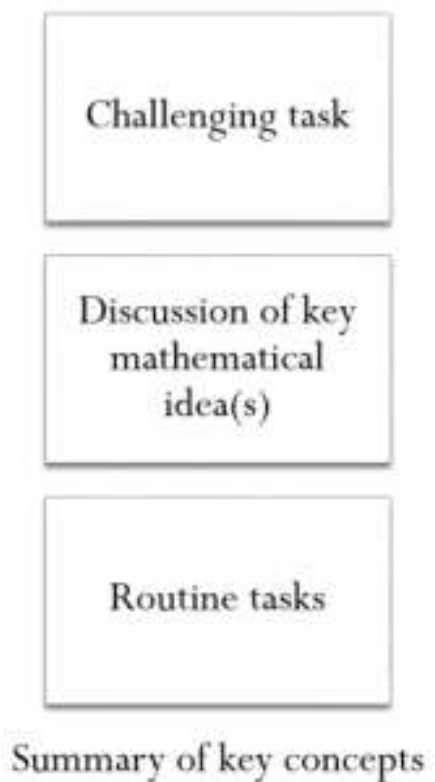

Discussion-First Approach

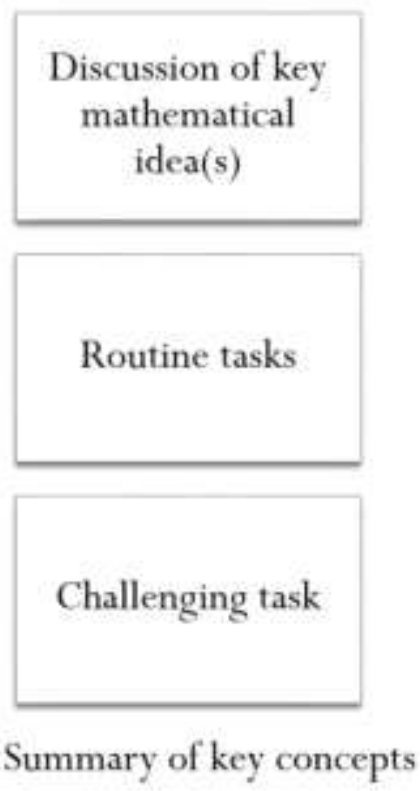

Figure 1: Contrasting the task-first approach with the discussion-first approach

Engaging students in a challenging task and launching a mathematics lesson with a task prior to instruction are two characteristics of a reform-oriented approach to mathematics instruction often considered together. My investigation systematically contrasted teaching with challenging tasks using a Task-First lesson structure (Task-First Approach) with that of a Discussion-First lesson 
structure (Discussion-First Approach) through the delivery of two programs of mathematics instruction to three composite grades $(\mathrm{n}=75)$ of Year 1 and 2 students ( 7 and 8 year olds) (see Figure 1).

All instruction took place within a single Victorian primary school. The school's 2015 enrolment was 258 students, with an Index of Community Socio-Educational Advantage (ICSEA) of 1042, slightly above the national average (1000). Only three per cent of students had a language background other than English.

I was responsible for developing the units of work (patterning unit, 16 content lessons; addition unit, 12 content lessons) and the respective lesson plans, and for leading the teaching during the sessions. By contrast, classroom teachers acted as relatively passive co-teachers, assisting with classroom management and providing occasional support and guidance to students to assist with the smooth running of the lessons. The active 'teaching' role of the classroom teacher was deliberately reduced in order to allow classroom teachers sufficient space to observe their students, and to ensure consistency in how the units of work were delivered across classes.

\section{What are challenging tasks?}

Challenging tasks are complex and absorbing problems with multiple solution pathways (Sullivan \& Mornane, 2014). According to Applebaum and Leikin (2014), for a mathematical task to be considered challenging, the level of complexity of a task should be optimized with respect to students' prior learning and expertise; a process that these authors link to Vygotsky's (1978) notion of a zone of proximal development. However, the idea of modifying a system's mechanics, that is, those aspects of a system over which agents have control (e.g., a task, a process), to impact on a system's dynamics, that is, the behavior of the individuals operating within that system, with a view to optimizing the outcomes generated by a system, is certainly not novel to education. Such an approach has precedent in fields as diverse as economics (e.g., Perloff, 2010), law (e.g., Hopper, 2017), and engineering (Rao, 2009).

In the context of teaching with challenging tasks in mathematics classrooms, such optimization is achieved primarily through the development of enabling and extending prompts as a central part of the task design process (Sullivan \& Mornane, 2014). Such prompts are intended to support differentiated instruction, through either providing a student with an 'in' into the main task (enabling prompts), or by providing further opportunities for students to build on their thinking (extending prompts). As noted earlier, as part of the current project, 28 different challenging tasks were developed; 16 relating to a unit of work on number patterning and 12 relating to a unit on addition and missing addend problems. Two examples of challenging tasks included in the current project, one from each unit, have been included below.

Patterning challenging task (Hundreds Chart Challenge: Fourth Time Luckier problem):

Starting at 0, I skip counted by 2's to 50, placing a counter on all the numbers I landed on. Next, I skip counted by 3 's to 50, again placing a counter on all the numbers I landed on. I did the same thing counting by 5's and 10's. There is only one number with four counters on it. What is the number? What if I continued skip counting to 100 instead of 50? How many numbers would I have landed on four times? What are these numbers? Do you notice any interesting patterns with these numbers? Can you keep this pattern going?

Addition and missing-addends challenging task (Number Bonds Equalling 100: Cupcake problem): 
John and Wendy loved baking. John wanted to try out a brand new cupcake recipe that had come to him in a dream. John and Wendy baked and baked all day, and finished the day with 100 cupcakes. They decided to share all the cupcakes between them. They both decided that John should get more cupcakes because he was the one who had dreamed up this new recipe. How many cupcakes might John have got? How many cupcakes might Wendy have got? Write down as many combinations as you can.

\section{Methodology}

The methodology underpinning this self-reflective component of my project can be appropriately described as "practitioner inquiry"; in particular, "using practice as a site for research" (CochranSmith \& Lytle, 2015, p. 39). This approach involves university-based researchers stepping into a K12 teaching role, in order to undertake research concerned with working out problems of practice. It needs to be noted that unpacking the complexities, barriers and enablers to teaching with challenging tasks from a first-person perspective was not the primary focus of my overall research project. However, my decision to maintain a teaching journal to systematically document observations and reflections regarding my own experience of delivering 84 lessons involving challenging tasks was an acknowledgment that my perspective as practitioner was a valuable lens through which to consider teachers' experiences of teaching with challenging tasks.

Interview data was analysed thematically; specifically an approach equating to "inductive thematic analysis" was pursued (Braun \& Clarke, 2006, p. 84). This process approximately mirrored the six stages proposed by Braun and Clarke, that is: 1) familiarisation with the data, 2) generating initial codes, 3) searching for themes, 4) reviewing themes, 5) defining and naming themes, and, finally, 6) producing the report.

\section{Teaching reflections}

The process of reflection is perhaps the primary means through which teachers make sense of, evolve, and refine their teaching practice (Kaezer, 2014). However, documented systematic reflections can also serve as a powerful means of influencing the practice of other teachers (Ramos-Rodriguez, Martinez, \& da Ponte, 2017). Consequently, as noted previously, during the delivery of the two units of work, I kept a daily journal. The intent of this journal was to capture both my observations in my capacity as researcher, and my teaching reflections in my capacity as an educator. Given that entries into this journal were undertaken prior to both interviews with teachers and students, and post program student outcome assessments, these journal entries can be considered largely independent of other sources of data collected throughout my project. Rather than focus on student learning outcomes (e.g., mathematical performance), and the perceived student experience of the program, which have been discussed elsewhere (see Russo \& Hopkins, 2017b, 2018), my analysis of the journal entries revolves around my first-hand experience of teaching the two units of work.

My reflections are organised around five particularly salient themes that emerged following review of my journal entries. The issue of lesson structure is not addressed separately, but rather is discussed insofar as it is embedded within each of these themes. These themes include: classroom management, maintaining and managing cognitive demand, time management, tensions between competing discussion objectives and tensions in task design. In order to illustrate and elaborate on some of these themes, extended quotations from my journal are included when deemed particularly relevant. 


\section{Classroom management}

In general, having well established routines and a clear, consistent lesson structure appeared to support classroom management, even in instances when students were engaged with challenging work. The advantage of clearly established routines and structures is that they enable students to psychologically and practically prepare themselves for what will be demanded of them in the lesson. Consequently, it was perhaps not surprising that, within each unit of work, classroom management issues, such as the time students took to transition between activities and general off-task behaviour, were, for the most part, less of a concern as the unit progressed, despite the content of the lessons becoming progressively more challenging.

Key routines and structures that were consistent across all lessons included: a) ensuring that all potential resources (e.g., bead-frames, hundred charts, enabling prompts) were located in the same place each lesson, b) at the beginning of each lesson, directing student attention to the electronic whiteboard for the launch of the task (Task-First Approach) or for the teacher-led discussion (Discussion-First Approach), c) displaying and stating the primary learning objective on a piece of A3 paper both at the beginning of the lesson and during the summary phase, d) explaining to students that each lesson would contain three essential phases, that is, a whole-group discussion, a worksheet containing routine tasks and work on a challenging task, and outlining the order in which these phases would occur.

With regard to classroom management and lesson structure, lessons involving the Discussion-First Approach generally felt calmer and more controlled than equivalent lessons involving the Task-First Approach. The Discussion-First Approach also tended to feel 'safer' from a teacher's perspective as the lessons generally unfolded in a more predictable manner. A key differentiating aspect was that, under the Discussion-First Approach, the material included in the teacher-led discussion was largely developed prior to the delivery of the lesson. By contrast, under the Task-First Approach, although student responses could be partly anticipated in advance, both the structure of the discussion and the specific student work samples supporting it were generally determined during the lesson.

However, there were also benefits to teaching through the Task-First Approach with regards to classroom management, provided that classroom management objectives are not conceived of narrowly as being limited to pursuing control, order and predictability. The need to emphasize a broader conceptualization of classroom management that encompasses positive aspects, such as the quality of student-teacher relationships, has been discussed elsewhere in the reform-teaching literature (Şen \& Sari, 2018). In this case, it was my experience that the Task-First Approach tended to generate a classroom environment that was more chaotic and unsettled but simultaneously more dynamic; with greater energy, spontaneity, participation and engagement.

Having drawn these distinctions, it is also worth noting that classroom management issues differed notably by cohort, independent of lesson structure. As I stated in a journal entry during the addition unit:

Across both units of work, Class B are the quietest group on the floor (as in, the less likely to contribute and engage in the discussion) and the loudest when working, which seems a particularly unsatisfying combination from a teaching point of view. Within Class $B$, there are perhaps seven students - around one-third of the class - who regularly, voluntarily contribute to discussion time. It would be no exaggeration to say that this number is at least double in the other two classes. 


\section{Maintaining and managing cognitive demand}

Strongly related to the theme of classroom management was the notion of maintaining and managing cognitive demand, particularly when the lesson began with the challenging task (Task-First Approach). I was prepared for this issue, having read literature prior to delivering the program outlining teacher discomfort with student struggle, and, in particular, perceived and actual pressure from students to reduce the level of cognitive demand (e.g., Darragh, 2013; Henningsen \& Stein, 1997; Tzur, 2008). Despite this knowledge, there were certainly occasions, particularly early in the program, where emergent classroom management issues, such as those arising from multiple students verbalising their confusion and frustration with a task, tested my resolve and commitment to maintaining a high level of cognitive demand. For example, I had two particular students in two different groups, who were more than capable mathematically, but would frequently act out (e.g., throw objects around the room, have tantrums) when they perceived a task or concept as too difficult. There were occasions when I was severely tested not to over-explain a novel task during its launch, particularly in the patterning unit. For example:

This lesson (i.e., first Hundred Chart Challenge) provided another example about the anxiety I, in my role as teacher, can encounter when I take students outside their comfort zone, and some yell out things like 'I can't do it'. It probably resulted in me providing some further 'priming' to each group, essentially carefully reading the task again to emphasise its various component parts, and suggesting they tackle the task one step at a time. This is support/ advice which I wasn't initially intending on providing. I will hopefully stay strong in the next session, given that students should now be familiar with the workings of these types of problems.

This commitment to maintaining a high level of cognitive demand, and the associated challenge of doing so, provides further justification for the decision to have the program implemented by the researcher, rather than by the respective classroom teachers. As I noted in another journal reflection:

With the first Fiona the Frog challenge, I 'primed' all the groups by letting them know that if they could count by ones, twos or threes it might be a help in solving this problem. In this manner, I connected the problem somewhat to prior learning, although within very definite constraints (e.g., I did not outline how to begin counting by threes). This is obviously a tough line to walk, and I think walking this line would be even more challenging if I was their regular classroom teacher and not approaching the program as a researcher (where I have an a priori commitment to maintaining a high level of cognitive demand). This is perhaps another reason why this study wouldn't work as well if I got the teachers to implement the lessons; there would just be far too much variability in terms of how they were implemented (i.e., variability amongst teachers in their level of comfort with student discomfort, and how much they 'told' students about how to approach the task).

\section{Time management}

Incorporating consolidating tasks into lessons involving challenging tasks is consistent with the literature (Sullivan et al., 2015). However, given our limited 55-minutes sessions (with an average of approximately 45 minutes engaged in mathematical work), the decision to include both a series of routine tasks and a challenging task in each lesson created a rigidity in structure that was at times problematic.

Although there are certainly benefits to teaching within a highly structured program (as noted under Classroom Management), one of the corresponding challenges to such an approach is the issue of time management. The current program was no exception. My aim was to spend between 10 and 15 minutes 'on task' for each of the three major components of the lesson (see Figure 1), and around 2 to 5 minutes on the lesson summary. Although my records demonstrate that this objective was, on average, achieved, the need to carefully 'watch the clock' to ensure that sufficient time was allocated 
to each aspect of the lesson added significant strain to the teaching experience, particularly in the early stages.

More specifically, during several lessons within both teaching structures (i.e., Task-First and Discussion-First), I felt that insufficient time was allocated to the challenging task segment of the lesson in particular (despite students spending on average 15 minutes exploring the challenging task). By contrast, it was often difficult to maintain the flow of the discussion component of the lesson beyond the initial seven to 10 minutes. Indeed, many students appeared to 'tune out' for the last five minutes or so of the discussion, regardless of whether the discussion occurred at the beginning of the lesson (i.e., Discussion-First Approach) or after work on the challenging task (i.e., Task-First Approach). This may have been in part a product of the young age of the children involved in the study.

In addition, the highly structured nature of the program and the corresponding time constraints were at times significant barriers to spontaneously exploring important mathematical ideas as they arose, and building on momentum generated within a lesson. Consider this example during the patterning unit when counting by fours was first introduced to Class B (which experienced this unit through the Discussion-First Approach).

Despite the lesson feeling somewhat overwhelming, the students did a good job of engaging with the challenging task and picking up the counting by fours patterns. I was very impressed by the quality of the student contributions during the Class B discussion which began the lesson. The students independently highlighted many of the patterns associated with counting by fours, as we generated and discussed this counting sequence on a hundred chart. For example:

"It counts every second number, so it is counting by 20s up and down" (Lochie)

"You have to skip three numbers" (Penelope)

"None of the numbers have any neighbours; they're smelly numbers" (Abby)

"You only count even numbers... you count every second even number" (Ash)

"There are two numbers on one row, and three numbers on the next row" (Teddy)

Ordinarily we would have run with this momentum and created some form of anchor chart pointing out what we notice when we count by fours. This would have allowed student ownership over many of the ideas highlighted (e.g., they could have put their names next to a particular idea with their contribution). This is one of the frustrations of running such a tight program in a research context; it can sometimes go against my teaching instincts. The minilesson had already run to 20 minutes- longer than desired-and it was necessary for the students to move on to the 'routine tasks'.

Time management was in many ways a particular challenge during the Discussion-First lesson structure. This was the case for several related reasons, many of which revolve around not being able to discuss the challenging task in any depth. First, during such lessons, there was not sufficient space to pursue interesting threads that emerged after students had grappled with the challenging task. Secondly, it was certainly limiting (and somewhat dissatisfying, from both a teacher and student perspective), to have the teacher summarise how one may have gone about solving the challenging task. Even though samples of student work were used during these summaries, it was difficult to incorporate meaningful student input, given the tight time frames during this final phase (i.e., two to five minutes). Thirdly, as this final part of the lesson is intended to function as a summary, it was not appropriate to explore student misconceptions that only became apparent once students had engaged 
with the challenging task. As is evident from the following journal entry, this inability to address misconceptions could feel like a lost learning opportunity.

With the Task-First Approach, there is more of a chance to address student misconceptions, because you can use student responses to explicitly discuss these when they are most relevant (i.e., when they are tackling the task). For example, during a Task-First lesson, Alannah counted by threes by generating the following pattern 3, 6, 9, 13, 16, 19 etc when working on the challenge. She concluded that Fiona the Frog wouldn't land on any lily pads (multiples of ten: 10, 20, 30 etc) if she hopped by threes, and therefore she should hop by twos. Although she was 'correct' in her answer (i.e., hopping by threes does not allow Fiona to land on enough lily pads), it was for the wrong reasons. However, because of the discussion after the task, we could examine whether this approach made sense, why Alannah might have thought it did in the first instance, and a strategy for getting around this (i.e., looking for diagonal and not vertical patterns when counting by threes; making sure we skip over two numbers, no less or no more). By contrast, when this same misconception emerged during a Discussion-First structure (i.e., when Jill was working on the challenging task), there was no time to address it in a meaningful manner. This was amplified by the fact that, like Alannah, Jill got the 'right' answer - and therefore may have even had her misconception validated during the lesson summary.

\section{Tensions between competing discussion objectives}

When delivering the two units of work, I experienced a clear tension between, on the one hand, leading students towards important mathematical ideas, and ensuring such ideas were appropriately articulated, and, on the other hand, letting students' authentic engagement with the task, and the students themselves, drive the discussion. A similar tension also existed between emphasising the most efficient student solution and celebrating the diversity of student responses, many of which were novel, idiosyncratic in terms of process and thus very much 'owned' by a particular student. In broad terms, such tensions can be framed as the need for the discussion to be instructionally-optimised coming into conflict with an attempt to ensure that it is appropriately student-centred.

Although such tensions are not novel to this program, with similar dialectics being highlighted in several other studies and commentaries (e.g., Baxter \& Williams, 2010; Lobato, Clarke, \& Burns, 2005; Stein et al., 2008), they remain considerably challenging to manage. Attempting to identify and synthesise these tensions whilst in the act of teaching is extremely cognitively demanding for the teacher, and a powerful reminder that teaching as a profession is so complex that it will always be considered as much an art as a science.

It is noteworthy that these tensions existed, to some extent, regardless of how the lesson was structured. In either instance, there was a constant need to balance the desire to achieve a specific learning objective with allowing students to take ownership of the discussion. As I noted after teaching a Task-First lesson early in the patterning unit:

Today we tackled the second Fiona the Frog problem. At the moment, with the Fiona the Frog problems, the discussion of the solutions has been more teacher-led than I intended, albeit with substantial student input. This is for a few reasons. Partly it is the complex structure of the problem (the lily pads, the lake) which seems a barrier to granting full control to student explanations (in contrast to more simply structured tasks like 'how many fingers in the room'). Also, there is essentially only one right answer to these problems, and many students seem to be approaching these problems in similar ways. Consequently, in order to 'build the explanation', I feel compelled to take charge and explore why counting by ones is too slow and why twos doesn't work (at least not for this task). It is not that I am stating the solution, but rather that I am leading students down a very particular pathway by asking specific questions of them which 
do not necessarily reflect how they went about solving the problem. I was conscious today that if I did not set the direction, the notion that counting by twos beginning on an odd number results in becoming 'stuck' on the odd number (one of the key learning objectives of the lesson) would not have emerged. This is largely because many of the students chose to count by threes first, either because they intuited that it was likely to be the correct answer, or because counting by the higher number first (and ruling it out if necessary) is the most efficient strategy. In more general terms, sequencing the student work samples for the Task-First condition so the discussion flows can be challenging, and is dependent on the particular student being able to articulate their thinking clearly. I can make the mistake of over-estimating some students' capacity to explain their strategy use (e.g., Ashleigh).

\section{Tensions in task design}

The final theme that emerged when analysing my experience of delivering the program of work related to an issue regarding task-design. Specifically, this theme encompasses the tension between the non-mathematical aspects of a problem solving task being prohibitively demanding when students first encounter a new problem context and structure, and the need to engage students through offering interesting and varied problem contexts. One means of framing this tension in terms of theoretical models of cognition is the need to minimise the extraneous (i.e., unnecessary) cognitive load associated with a task on the one hand (Sweller, 2010), with the need to promote state curiosity and novelty to prime the brain for learning on the other (Oudeyer, Gottlieb, \& Lopes, 2016).

Although this tension was less of an issue during the more consistently structured addition unit, it arose frequently during the more novel patterning unit. Consistently across the patterning unit, the first lesson adopting a particular theme was generally experienced as difficult and demanding to teach and learn, as many students appeared to struggle to understand what the challenging task entailed, before they even considered what was required of them mathematically. However, subsequent tasks with a similar structure were often experienced as relatively straightforward. Two of the more difficult to comprehend themes were the Fiona the Frog tasks (Russo, 2016) and the Hundred Chart Challenges (Russo, 2019), which arguably justifies the fact that each of these themes comprised three lessons, whilst the other themes involved only two lessons. Consider three related journal entries recorded during the corresponding Fiona the Frog challenging tasks.

Challenging Task 1: As a group, students were frustrated with the Fiona the Frog problem. Comprehending the structure of the problem was a clear challenge.

Challenging Task 2: Overall the lessons ran more smoothly today, which reflected the fact that students were more familiar with the context of the Fiona the Frog challenge, and also the fact that the routines are more established.

Challenging Task 3: Most of the students had success with the challenging task activity todaythey've certainly come a long way since Monday! Again, it shows the importance of routine, and building on similar problem structures. Students adapt and absorb - they learn the rules of the game (if these are clearly stated), and internalise them.

\section{Concluding thoughts}

Developing and teaching these two units of work was rewarding and stimulating, however extremely intellectually and emotionally demanding, perhaps unsustainably so. Would such an experience be typical for a teacher endeavouring to build daily mathematical instruction around challenging tasks, as I did for this project? It is difficult to conclude definitively. To some extent, the pressures I experienced were a consequence of the dual teacher-researcher role I occupied whilst delivering the lessons, which 
clearly adds to the toil of teaching 'in the moment' and can generate internal conflict, as has been reported elsewhere (Tabach, 2006). However, it also needs to be remembered that having students' regular classroom teacher in the room allowed me to focus on facilitating content delivery and engaging students in mathematical thinking and discussion, rather than on classroom management and behavioural issues. It is difficult to weigh up the relative impact of these two counterbalancing forces, however my sense is that teaching effectively with challenging tasks on a regular basis would likely be at least as demanding for a generalist early years classroom teacher in a primary school.

There is broad acknowledgement that formal teacher reflections, such as those provided in the current paper, could be a powerful process for both improving one's own teaching practice, and supporting the professional development of other teacher practitioners (Ramos-Rodriguez et al., 2017). The experience of teaching over 80 lessons involving challenging tasks to different groups of students, maintaining a reflective journal, and subsequently analyzing this journal and coalescing these reflections, has certainly had a positive impact on my own teaching practice. Perhaps most critically, this process has taught me that teaching with challenging tasks demands resilience from myself as a teacher as well as my students. Reflecting on my own personal experience, I would conclude that a resilient teacher is a prepared teacher.

However, more generally, I hope these observations from my experience delivering these two intensive units built around challenging tasks are of some value to teacher-educators and mathematics researchers attempting to support teachers across the system to incorporate more of these types of tasks into their instruction. I believe that professional learning programs that aim to support teachers in this space should consider explicitly and proactively addressing the five themes that arose from my reflections, that is: classroom management, maintaining and managing cognitive demand, time management, tensions between discussion objectives, and tensions in relation to task design. In this way, teachers can anticipate some of the difficulties and tensions that are likely to arise in their classroom when teaching with challenging tasks, and plan how they will address these issues.

\section{Acknowledgements}

I wish to thank the students and teachers who participated in and supported this project. I would also like to thank reviewers for their constructive feedback on this paper. This project is supported by MUHREC Human Ethics Approval CF14/3883 2014002000 .

\section{References}

Applebaum A., \& Leikin R. (2014). Mathematical challenge in the eyes of the beholder: Mathematics teachers' views. Canadian Journal of Science, Mathematics and Technology Education, 14(4), 388-403.

Baxter, J. A., \& Williams, S. (2010). Social and analytic scaffolding in middle school mathematics: Managing the dilemma of telling. Journal of Mathematics Teacher Education, 13(1), 7-26.

Braun, V., \& Clarke, V. (2006). Using thematic analysis in psychology. Qualitative Research in Psychology, $3(2), 77-101$.

Charalambous, C. Y. (2008). Mathematical knowledge for teaching and the unfolding of tasks in mathematics lessons: Integrating two lines of research. In O. Figueras, J. Cortina, S. Alatorre, T. Rojano, \& A. Sepúlveda (Eds.), Proceedings of the 32nd conference of the International Group for the Psychology of Mathematics Education (pp. 281-288). Morelia, Mexico: PME.

Cochran-Smith, M., \& Lytle, S. L. (2015). Inquiry as stance: Practitioner research for the next generation. New York: Teachers College Press.

Darragh, L. (2013). Sticking with it or doing it quickly: What performances do we encourage in our mathematics learners? In V. Steinle, L. Ball \& C. Bardini (Eds.), Proceedings of the 36th annual conference of the Mathematics Education Research Group of Australasia (pp. 218-225). Melbourne, VIC: MERGA.

Giacomone, B., Beltrán-Pellicer, P., \& Godino, J. D. (2019). Cognitive analysis on prospective mathematics teachers' reasoning using area and tree diagrams. International Journal of Innovation in Science and 
Mathematics Education (formerly CAL-laborate International), 27(2), 18-32.

Henningsen, M., \& Stein, M. K. (1997). Mathematical tasks and student cognition: Classroom-based factors that support and inhibit high-level mathematical thinking and reasoning. Journal for Research in Mathematics Education, 28(5), 524-549.

Hopper, B. R. (2017). Amici Curiae in the United States Supreme Court and the Australian High Court: A lesson in balancing amicability, 51 J. Marshall L. Rev. 81 (2017). The John Marshall Law Review, 51(1), 81-106.

Keazer, L. M. (2014). Teachers' learning journeys toward reasoning and sense making. In: J.J. Lo, K.R. Leatham \& L. Van Zoest (Eds), Research trends in mathematics teacher education (pp. 155-180). Springer, Cham.

Lobato, J., Clarke, D., \& Ellis, A. B. (2005). Initiating and eliciting in teaching: A reformulation of telling. Journal for Research in Mathematics Education, 36(2), 101-136.

Oudeyer, P. Y., Gottlieb, J., \& Lopes, M. (2016). Intrinsic motivation, curiosity, and learning: Theory and applications in educational technologies. In B. Studer \& S. Knecht (Eds.), Progress in Brain Research (Vol. 229, (pp. 257-284), Elsevier.

Perloff, J. M. (2010). Microeconomics: Global edition (6th ed.). Boston, MA: Pearson Addison Wesley

Ramos-Rodríguez, E., Martínez, P. F., \& Da Ponte, J. P. (2017). An approach to the notion of reflective teacher and its exemplification on mathematics education. Systemic Practice and Action Research, 30(1), 85-102.

Rao, S. S. (2009). Engineering optimization: Theory and practice. New York, NY: John Wiley \& Sons.

Ridlon, C. L. (2009). Learning mathematics via a problem-centered approach: A two-year study. Mathematical Thinking and Learning, 11(4), 188-225.

Russo, J. (2015a). Surf's up: An outline of an innovative framework for teaching mental computation to students in the early years of schooling. Australian Primary Mathematics Classroom, 20(2), 34-40.

Russo, J. (2015b). Teaching with challenging tasks: Two 'how many' problems. Prime Number, 30(4), 9-11.

Russo, J. (2016). Teaching with challenging tasks: Hopping with Fiona the Frog. Prime Number, 31(2), 10-11.

Russo, J. (2019). Teaching with Challenging Tasks: Experiments with Counting Patterns. Primary Mathematics, 23(1), 11-16.

Russo, J., \& Hopkins, S. (2017a). Examining the impact of lesson structure when teaching with cognitively demanding tasks in the early primary years. In S. L. A. Downton, \& J. Hall (Ed.), Proceedings of the 40th Annual Conference of the Mathematics Education Research Group of Australasia (pp. 450-457). Melbourne, Australia: MERGA.

Russo, J., \& Hopkins, S. (2017b). Student reflections on learning with challenging tasks: 'I think the worksheets were just for practice, and the challenges were for maths'. Mathematics Education Research Journal, 29(3), 283-311.

Russo, J., \& Hopkins, S. (2018). Teaching primary mathematics with challenging tasks: How should lessons be structured? The Journal of Educational Research. doi:doi:10.1080/00220671.2018.1440369

Şen, Ö. F., \& Sari, U. (2018). From traditional to reform-based teaching beliefs and classroom practices of elementary science teachers. International Journal of Innovation in Science and Mathematics Education (formerly CAL-laborate International), 26(6), 76-95.

Stein, M. K., Engle, R. A., Smith, M. S., \& Hughes, E. K. (2008). Orchestrating productive mathematical discussions: Five practices for helping teachers move beyond show and tell. Mathematical Thinking and Learning, 10(4), 313-340.

Sullivan, P., Askew, M., Cheeseman, J., Clarke, D., Mornane, A., Roche, A., \& Walker, N. (2015). Supporting teachers in structuring mathematics lessons involving challenging tasks. Journal of Mathematics Teacher Education, 18(2), 123-140.

Sullivan, P., \& Mornane, A. (2014). Exploring teachers' use of, and students' reactions to, challenging mathematics tasks. Mathematics Education Research Journal, 26(2), 193-213.

Sweller, J. (2010). Element interactivity and intrinsic, extraneous, and germane cognitive load. Educational Psychology Review, 22(2), 123-138.

Tabach, M. (2006). Research and teaching - Can one person do both? A case study. In J. Novotna (Ed.), Proceedings of the 30th Conference of the International Group for the Psychology of Mathematics Education (pp. 233-240). Prague, Czech Republic: PME.

Thomas, J. A., \& Monroe, E. E. (2006). Self-study of a teacher's journey toward standards-based mathematics teaching. Studying Teacher Education, 2(2), 169-181.

Tzur, R. (2008). A researcher perplexity: Why do mathematical tasks undergo metamorphosis in teacher hands? In O. Figuras, J. Cortina, S. Alatorre, T. Rojano, \& A. Sepulveda (Eds.), Proceedings of 32nd conference of the International Group for the Psychology of Mathematics Education (pp. 139-147). Morelia: PME.

Vygotsky, L. S. (1978). Mind in society: The development of higher psychological processes. Cambridge, MA: Harvard University Press. 